Supporting Information for

\title{
A Near-Infrared Dual-Emission Ratiometric Fluorescence Imaging Nanoprobe for Real-Time Tracing the Generation of Endogenous Peroxynitrite in Single Living Cell and in Vivo
}

Pengxiang Lin, Dongxia Chen, Liangliang Zhang,* Jiayao Xu, Yong Huang, and Shulin Zhao*

State Key Laboratory for the Chemistry and Molecular Engineering of Medicinal

Resources, Guangxi Normal University, Guilin, 541004, China.

\section{Table of contents}

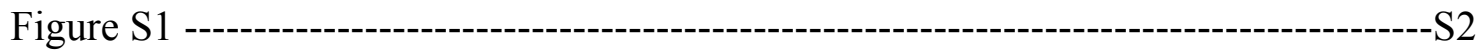

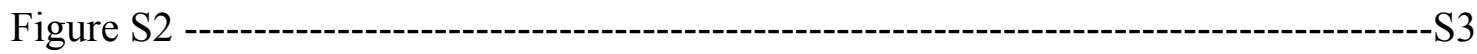

Figure S3 -----------------------------------------------------------------------------------------S3

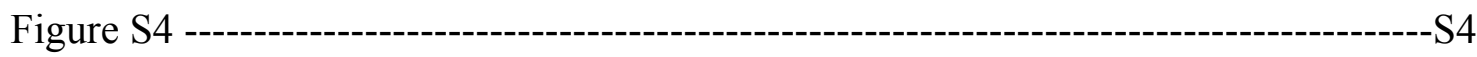

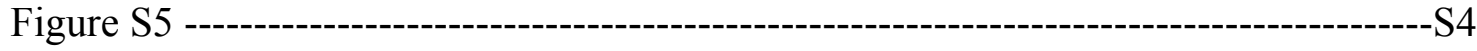

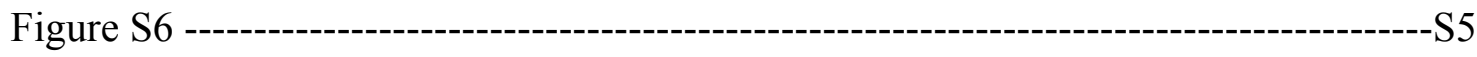

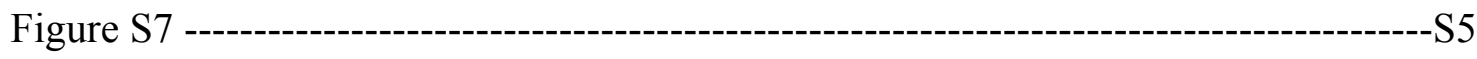

Figure S8 --------------------------------------------------------------------------S6

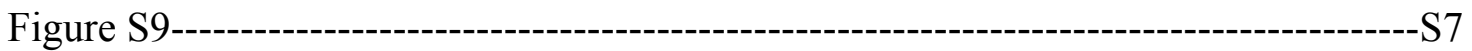



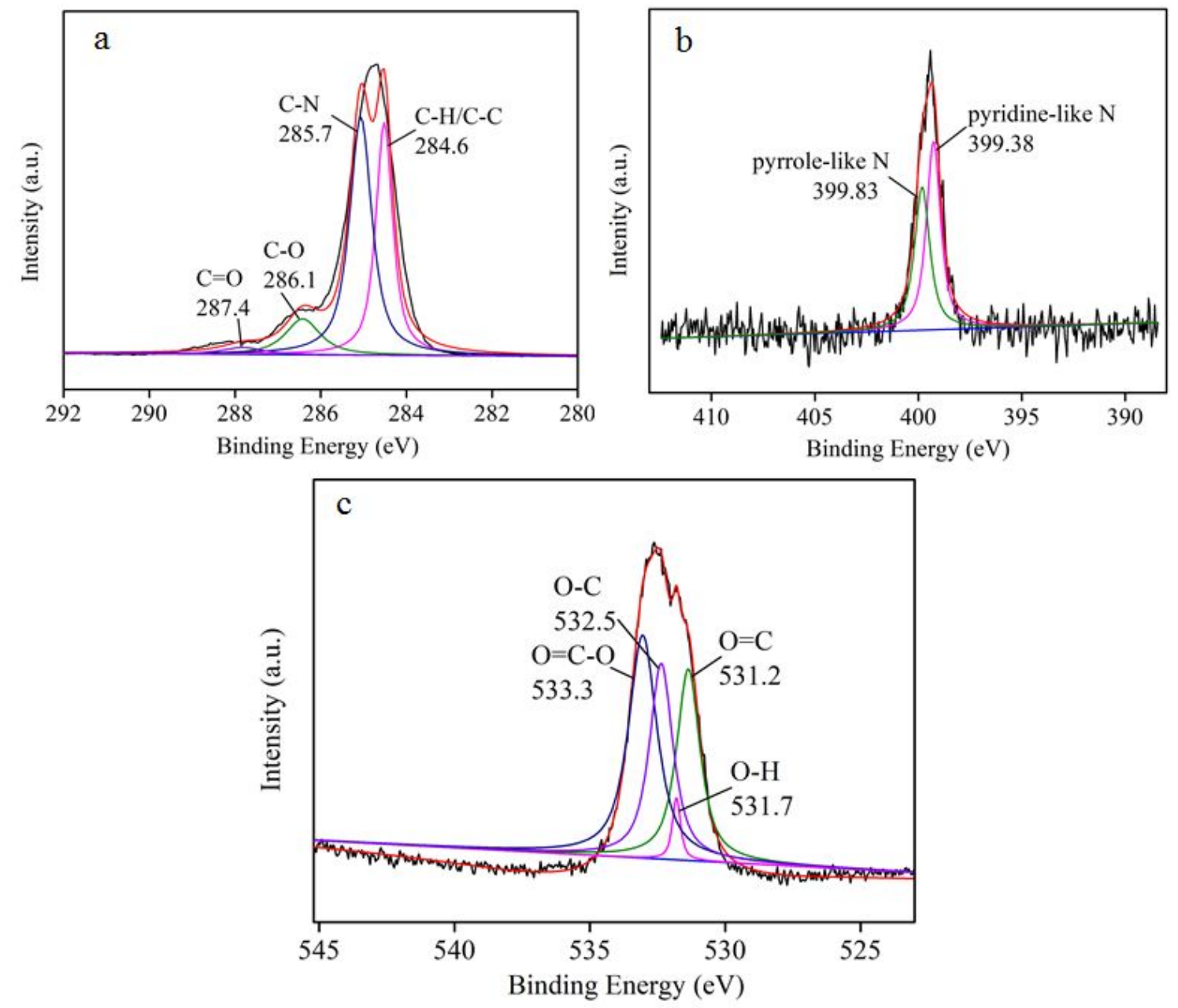

Figure S1. High-resolution XPS spectra of NI-BQDs for C1s (a), N1s (b) and O1s (c). 


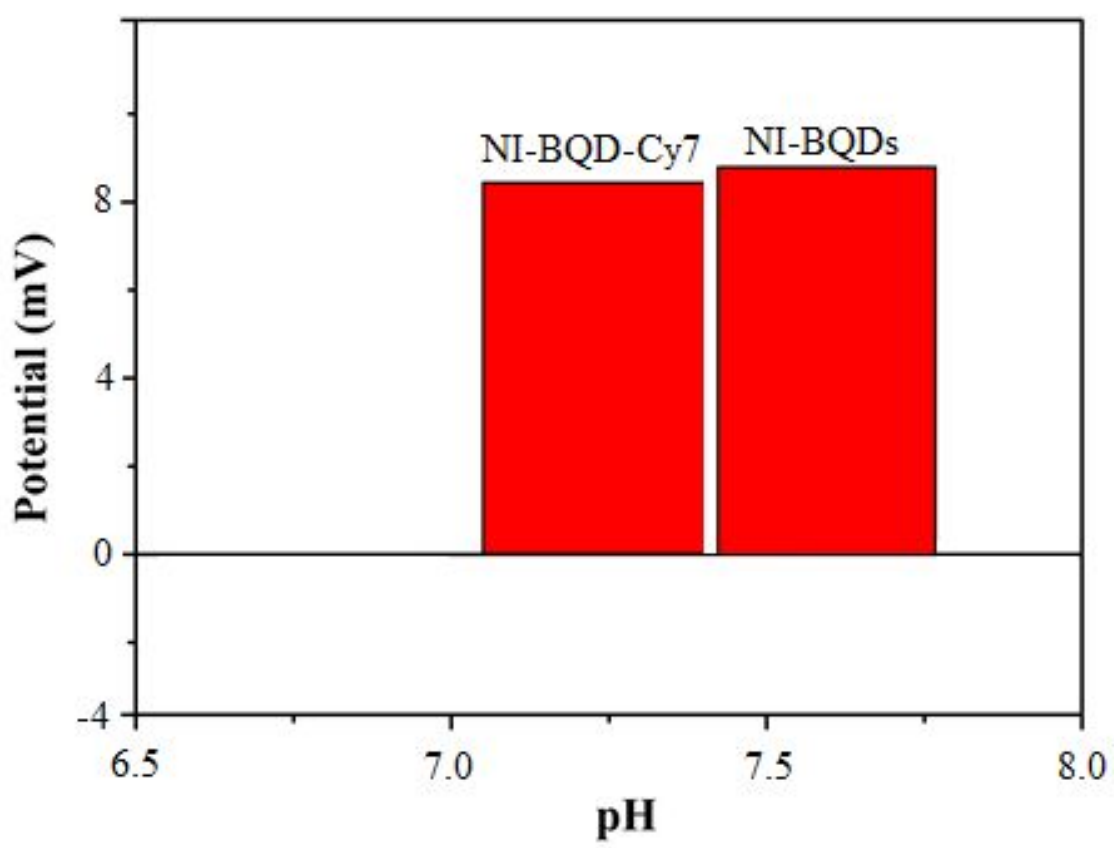

Figure S2. Zeta-potential of the as-prepared NI-BQDs and NI-BQD-Cy7.

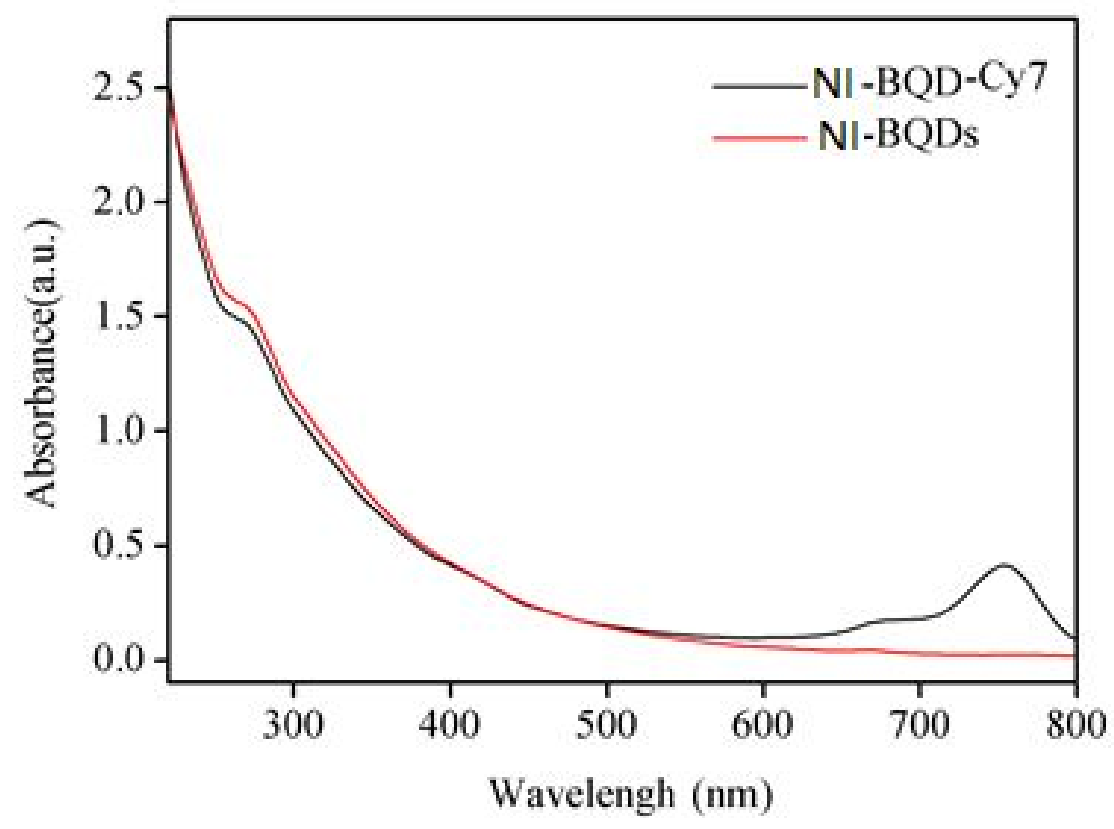

Figure S3. The UV-Vis spectra of NI-BQDs and NI-BQD-Cy7. 


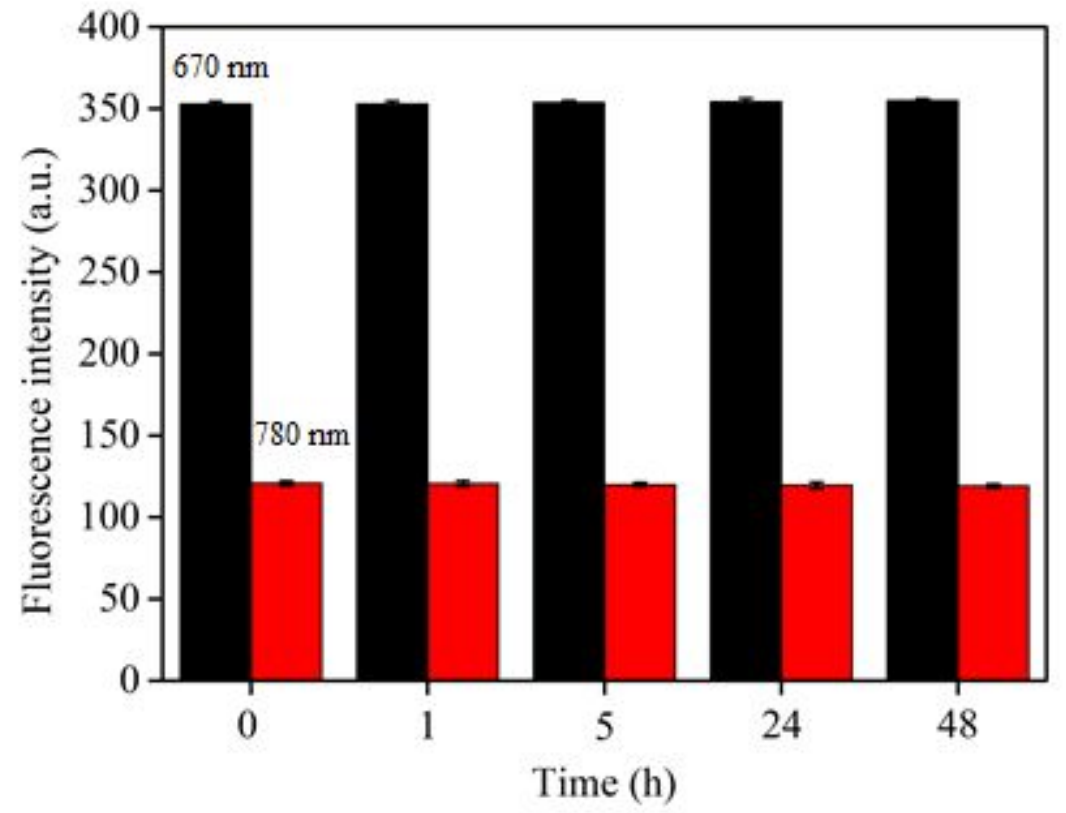

Figure S4. Stability of NI-BQD-Cy7 fluorescent nanoprobe in aqueous solution.

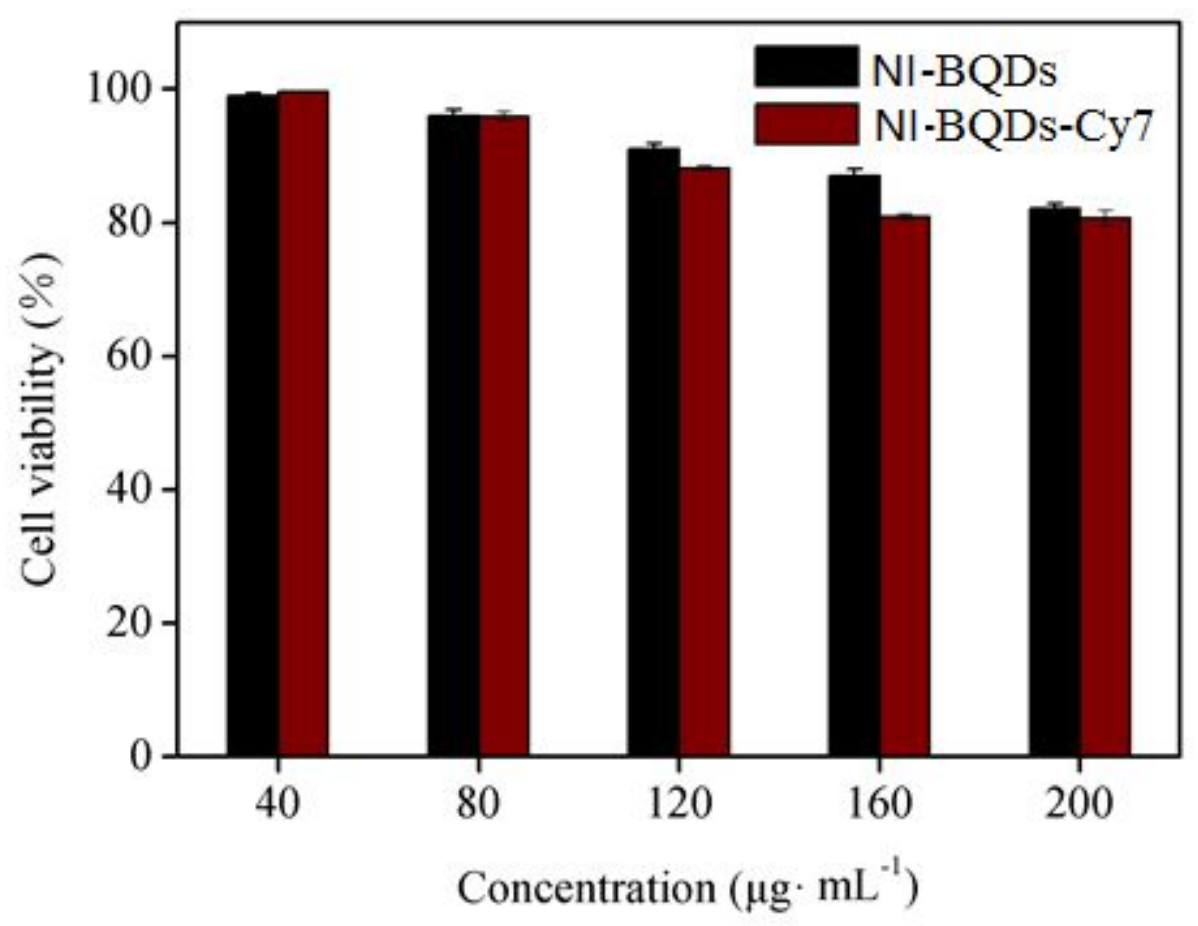

Figure S5. Cytotoxicity of the NI-BQDs and NI-BQD-Cy7 nanoprobes. 


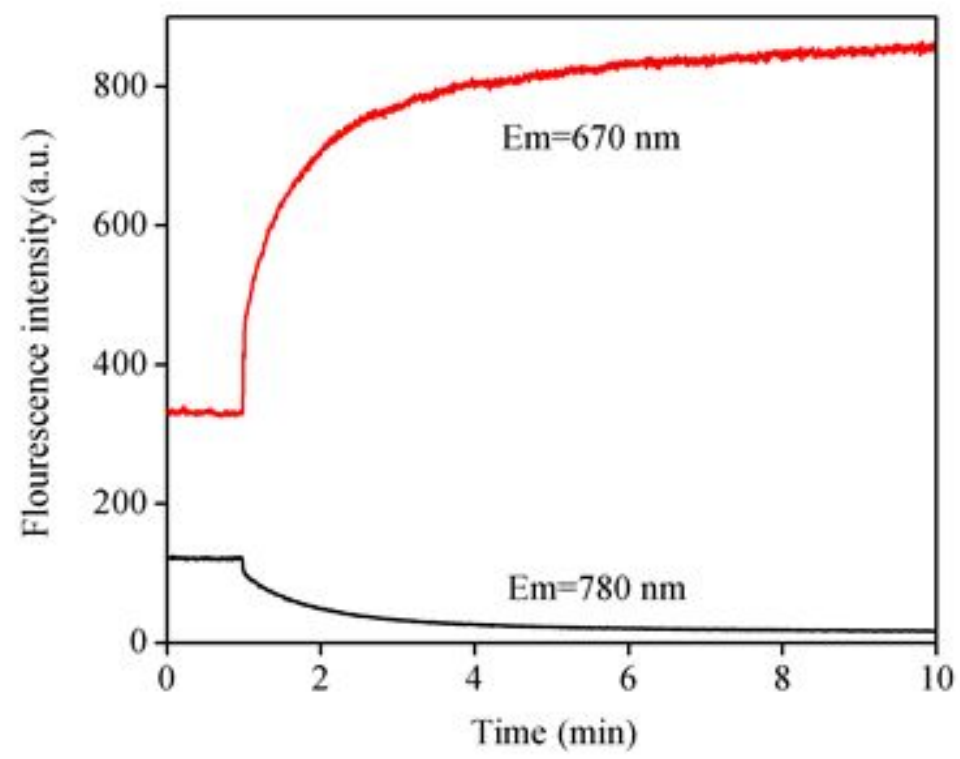

Figure S6. Kinetics curve for the change of fluorescence intensity of NI-BQD-Cy7 after the addition of $\mathrm{ONOO}^{-}$.

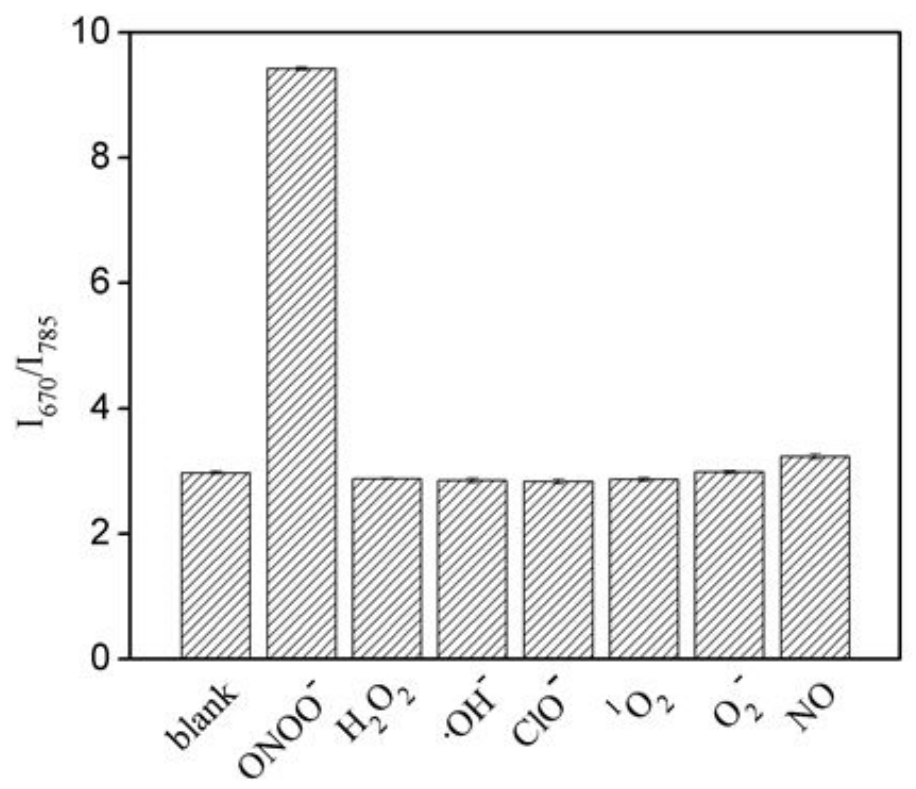

Figure S7. Selectivity of the NI-BQD-Cy7 nanoprobe in the presence of other bioactive RNS and ROS molecules. 


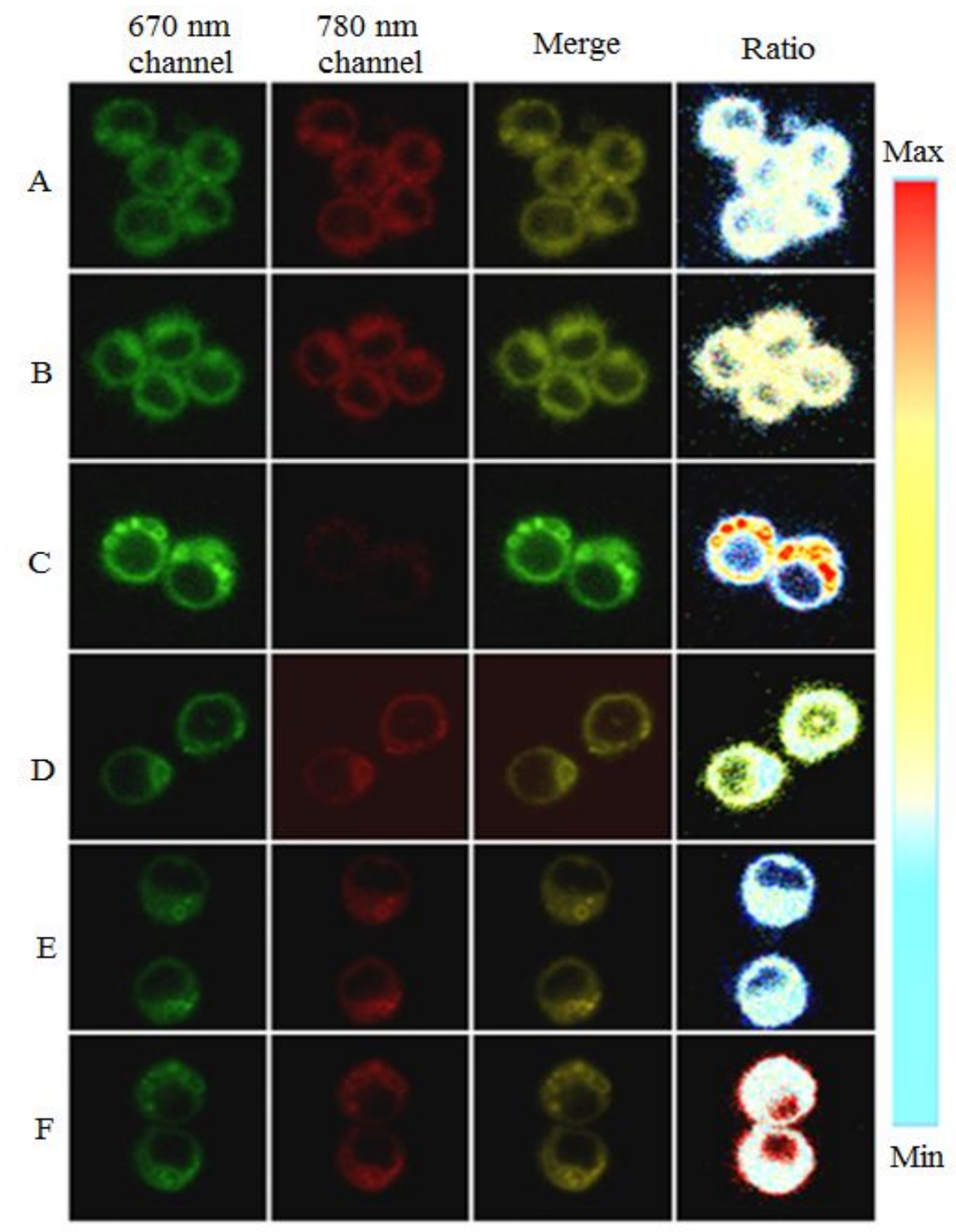

Figure S8. Dual channel ratiometric fluorescence images of exogenous $\mathrm{ONOO}^{-}$in living cells. The RAW264.7 cells solution containing NI-BQD-Cy7 nanoprobe was incubated with PBS solution (A), $100 \mu \mathrm{M}$ SIN-1 solution (B), $1 \mathrm{mM} \mathrm{SIN-1} \mathrm{solution} \mathrm{(C),} \mathrm{a} \mathrm{mixed}$ solution contining $1 \mathrm{mM}$ SIN-1 and $100 \mu \mathrm{M}$ tetracycline (D), $100 \mu \mathrm{M}$ MSB (E) and 500 $\mu \mathrm{M}$ NOC-18 solution (F). 


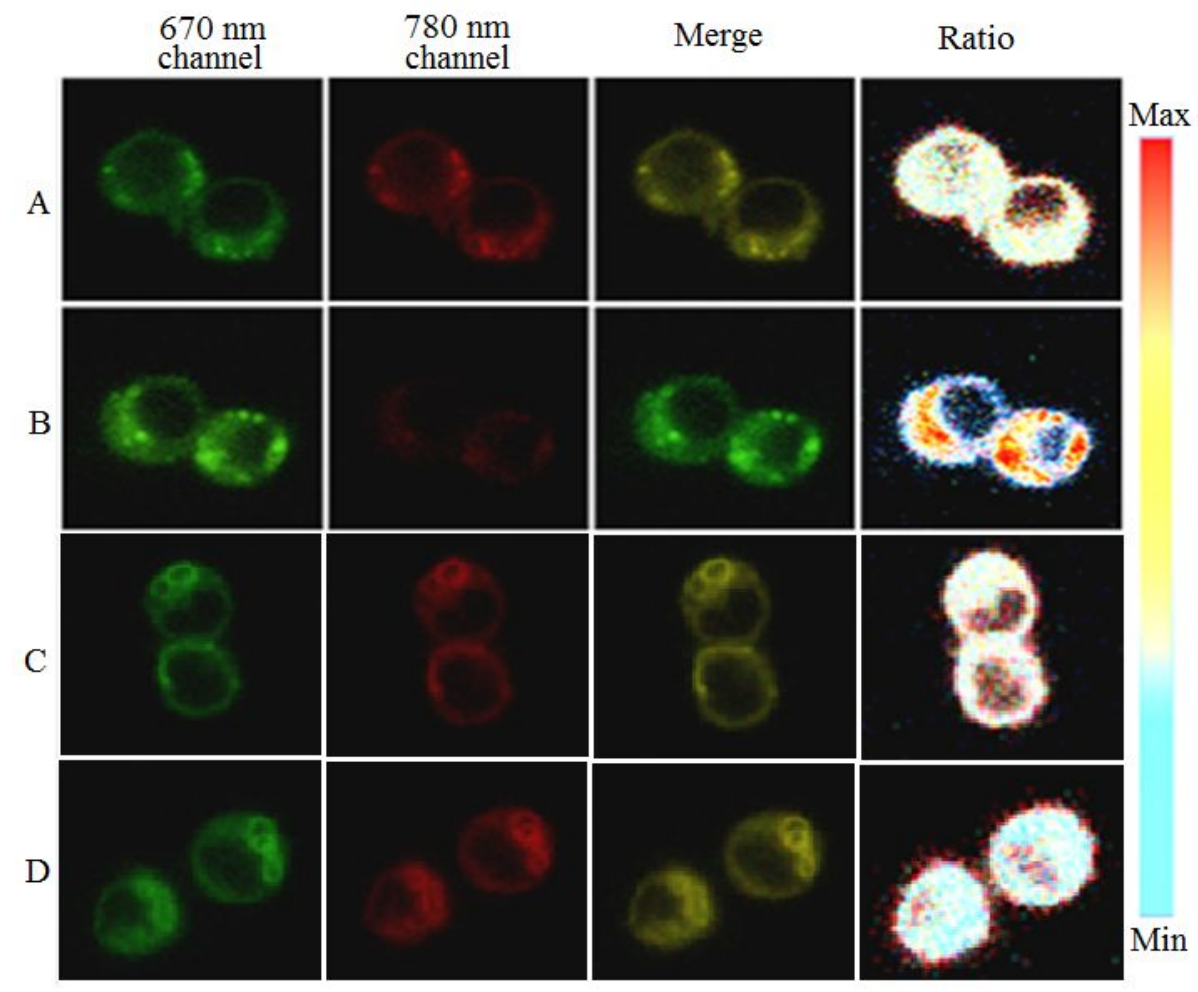

Figure S9. Dual channel ratiometric fluorescence images of endogenous $\mathrm{ONOO}^{-}$in living cells. The RAW264.7 cells solution containing NI-BQD-Cy7 nanoprobe was incubated with PBS solution (A), a mixed solution contining $50 \mathrm{ng} / \mathrm{mL}$ INF- $\gamma, 1 \mu \mathrm{g} / \mathrm{mL}$ LPS and $25 \mathrm{nM}$ PMA (B), a mixed solution contining $50 \mathrm{ng} / \mathrm{mL}$ INF- $\gamma, 1 \mu \mathrm{g} / \mathrm{mL}$ LPS, $25 \mathrm{nM}$ PMA and $100 \mu \mathrm{M} 1400 \mathrm{~W}$ (C), a mixed contining $50 \mathrm{ng} / \mathrm{mL}$ INF- $\gamma, 1 \mu \mathrm{g} / \mathrm{mL}$ LPS, $25 \mathrm{nM}$ PMA and $100 \mu \mathrm{M}$ apocynin (D). 